\title{
Bestiario profano
}

María José Gallardo-Rubio

L a oscuridad revela cosas que no son visibles a la luz. En la penumbra, los sentidos se ven obligados a agudizarse; instintivamente se presta mayor atención a los sonidos, las texturas, los olores, que surgen inesperados e irreconocibles sin la interferencia de la luz. Andamos con tiento e indecisión en la oscuridad y la imaginación fácilmente desata espejismos, delirios y alucinaciones. El silencio y la inmovilidad de las cosas nos aumentan el pulso y las sensaciones se vuelven más intensas. La oscuridad nos acerca a la experiencia interior, nos conduce a examinar nuestra mente, confesar pensamientos, detonar emociones, satisfacer deseos. Sin darnos cuenta ya estamos en esa espiral íntima.

La producción visual de Anel Martínez — Larvae es su alter ego artístico, su heterónimo - se gesta primordialmente en la oscuridad. Sus pulsiones artísticas encuentran hogar en las penumbras de la noche o en las profundidades de los mares; en la oscuridad produce atmósferas ominosas, quizá su sello estilístico. Larvae trabaja principalmente en blanco y negro, con tinta china y papel de algodón; juega con sombras y texturas para dar vida al terror, la muerte, el insomnio, el deseo y la locura en criaturas fantásticas, infernales, oscuras, en la mayoría de los casos vinculadas con aquello que Roger Caillois llamaba el lado 'nefasto' de lo sagrado.

$\mathrm{Su}$ inspiración se solaza en diversos terrenos, en la música, la ciencia ficción, los cómics, el folclor germano, en mitologías antiguas y, sobre todo, la cultura popular. Hay una relación muy cercana entre la música y su plástica — seguramente también en su proceso creativo_-; muchas de sus ilustraciones han sido inspiradas o creadas especialmente para bandas de rock y metal. 1000mods y Thule Ep "I" capturan el desgarrar de una guitarra eléctrica o la explosión de una batería. 
Su obra parece una fusión entre el grabado y la cultura popular, como si el imaginario de las calaveras de la música metal se fusionara con la técnica de los grabados de Durero. Me refiero a tres en particular, Lucifer, Demon y Día de los muertos. Con esa fusión, las imágenes de Larvae bien podrían encontrarse en un museo, una playera, en el sticker de una moto chopper o en la etiqueta de una cerveza bock.

En el universo artístico de Larvae no existe la realidad como la conocemos, cotidiana, concreta, repetitiva. Ella la subvierte y hace prevalecer la fantasía oscura donde se mezclan el sueño, el terror, el miedo, pero también el deseo, la belleza y el erotismo, quizá con la profundidad romántica de Heinrich Füssli.

Larvae disecciona su propio bestiario profano. En él hay tentadoras sirenas con tentáculos y lamias de ojos negros que aguardan pacientes y lascivas alguna víctima. Brujas con los ojos en blanco por algún codiciado éxtasis. Demonios, cabras y zombis podridos y viciosos que no se conforman con la luz y el cielo, sino que se alzan como dueños de ese infierno, lugar de delirio y pesadillas, lugar sin sol.

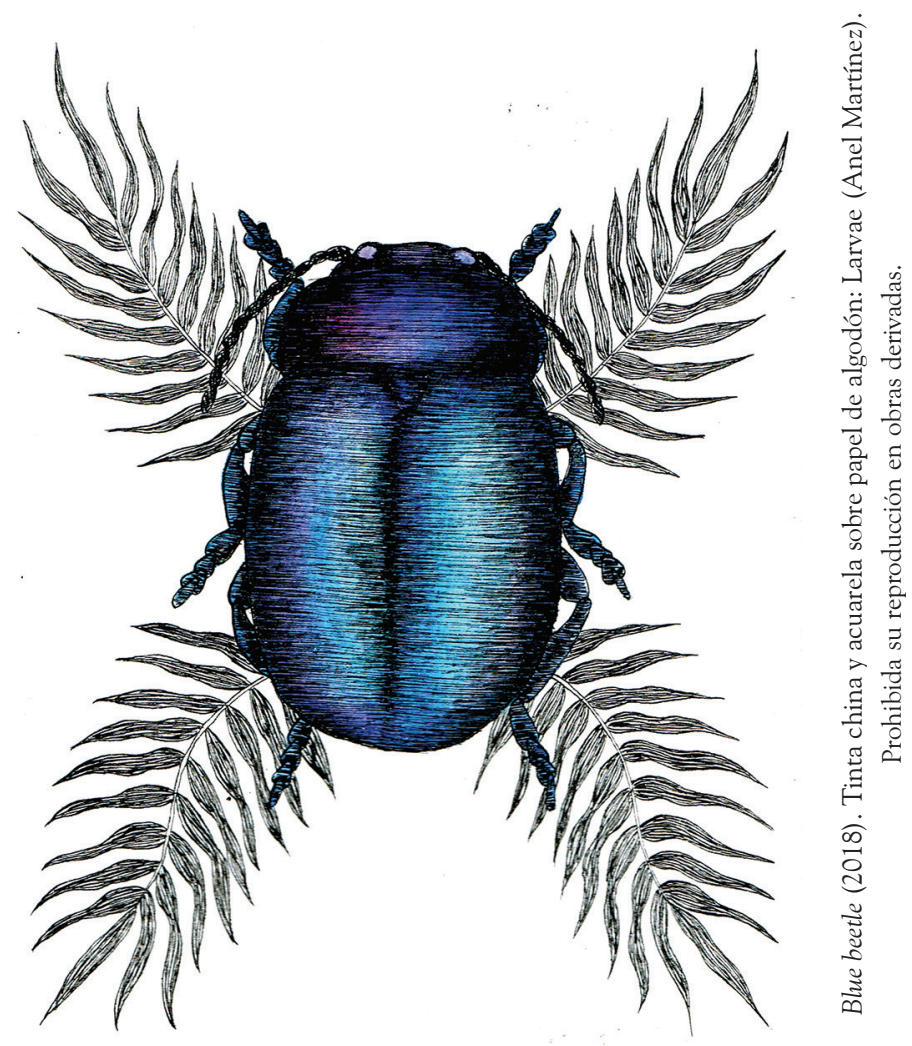




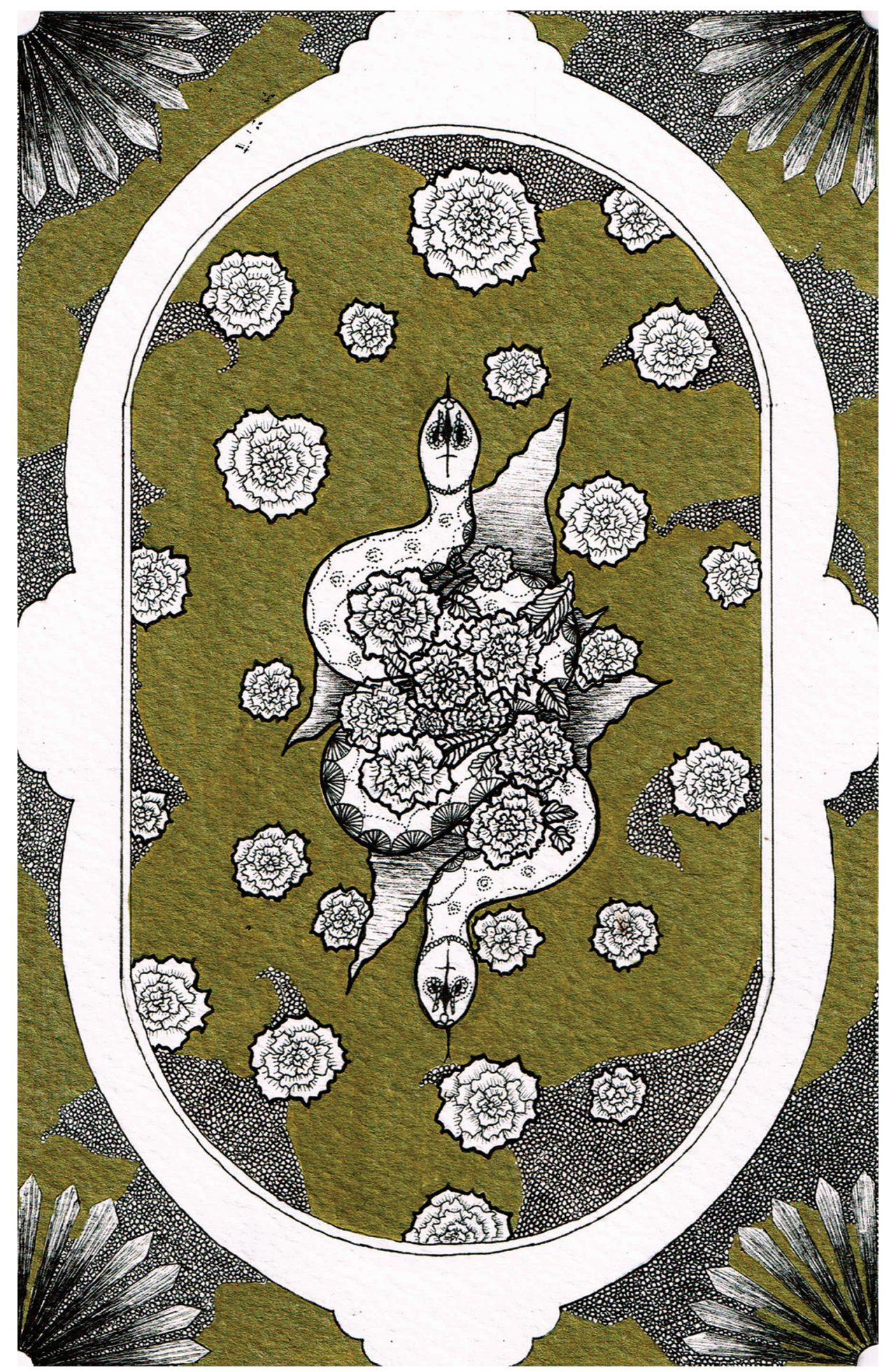

S by S (2017). Tinta china y plumón dorado sobre papel de algodón: Larvae (Anel Martínez). Prohibida su reproducción en obras derivadas. 


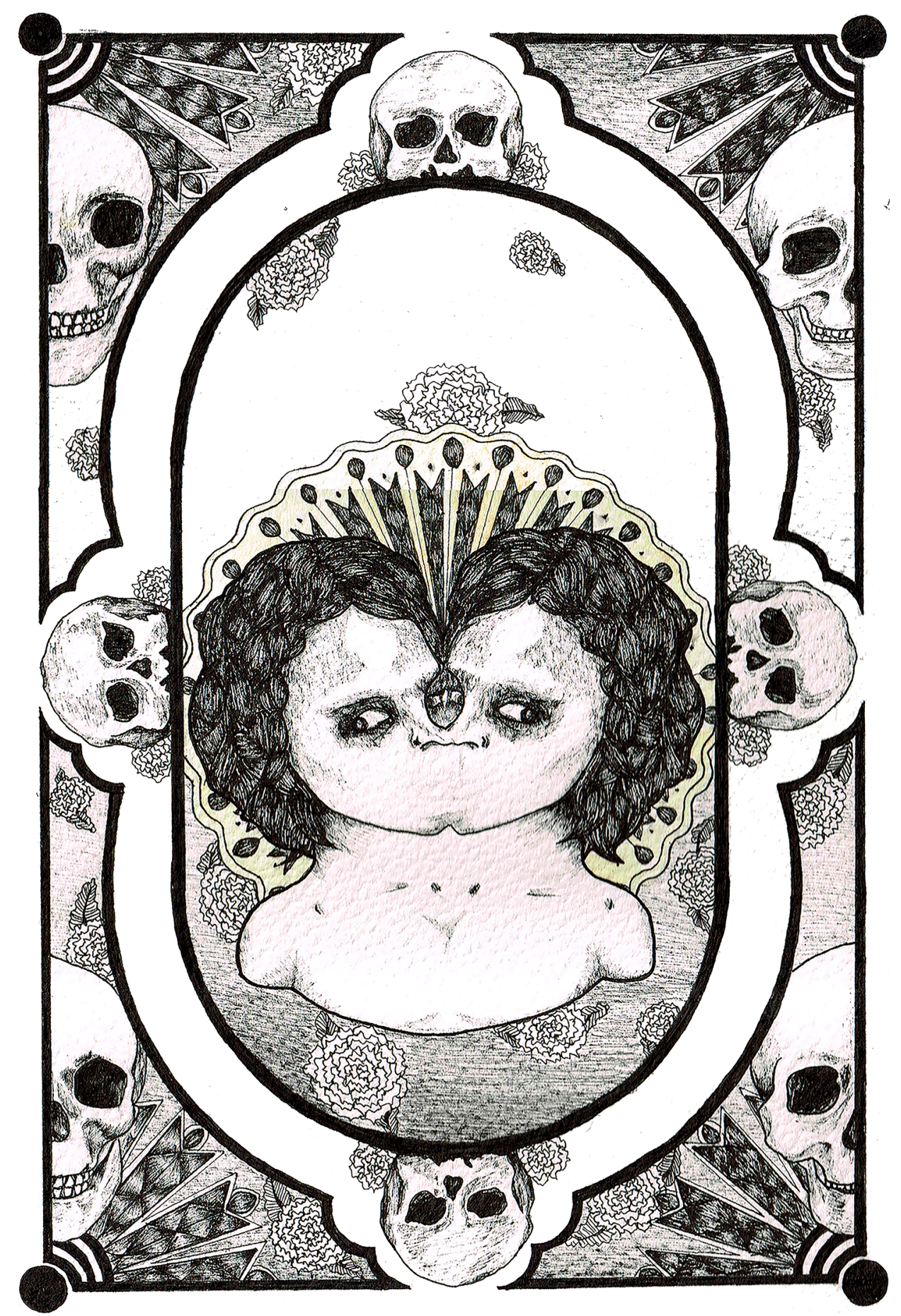

Adiós Narciso (2015). Tinta china sobre papel de algodón: Larvae (Anel Martínez).

Prohibida su reproducción en obras derivadas. 
También el Wolpertinger, animal fantástico del folclor germano con cuerpo de ardilla, cabeza de conejo, astas de ciervo y alas de faisán que corretea por las planicies yermas del algodón; o el Swamp monster, descendiente del horror cósmico que pareciera engullir la misma oscuridad.

Con ilustraciones como el autorretrato amordazado, las serpientes bicéfalas o el grotesco Adiós Narciso no se puede evitar pensar en el doble, el doppelgänger, la sombra siniestra, deforme y monstruosa que emerge tal vez como signo de simetría, de duplicación especular o tal vez como augurio de muerte.

Larvae presenta otra serie a color, la de los escarabajos verdes y azules vibrantes como salidos de otra dimensión que se arrastran en ese mundo sin luz, igual de cromáticos que las tóxicas cantáridas, invocadas por el espíritu medieval para brebajes.

A todo este bestiario no lo amenaza el tiempo, porque habitan una dimensión donde esa idea no existe. La realidad ordinaria que nos rodea no es suficiente para Larvae. Ella prefiere conjurar un universo alterno, extraordinario, donde se puedan desatar las fuerzas subterráneas y oceánicas que acechan y tientan al hombre a los abismos y al vértigo. Porque una vez franqueada esa barrera pareciera que no hay retorno a la luz.

Uno de sus rasgos más interesantes es que, mediante el hábil manejo de la tinta, sus imágenes fluyen en rápidos trazos, en pinceladas oscuras, densas, que palpitan color negro y adquieren la forma de bestias y quimeras que reptan en la imaginación como terrores nocturnos, angustias vueltas realidad, susurros que no quisiéramos escuchar. Larvae ilustra como cuestionando los deseos, temores y prohibiciones más arraigados del hombre, y esa búsqueda es el origen y motivación de su producción plástica.

Larvae utiliza la oscuridad para revelar. Mirar su obra es abandonarse a las fuerzas contenidas que turban el vivir de los temerosos. Provoca temor, perturbación, y al mismo tiempo logra que quieras mirar dos veces, a detalle, acercarte lo más posible a la imagen para hallar cada trazo y escucharlos hablar. 


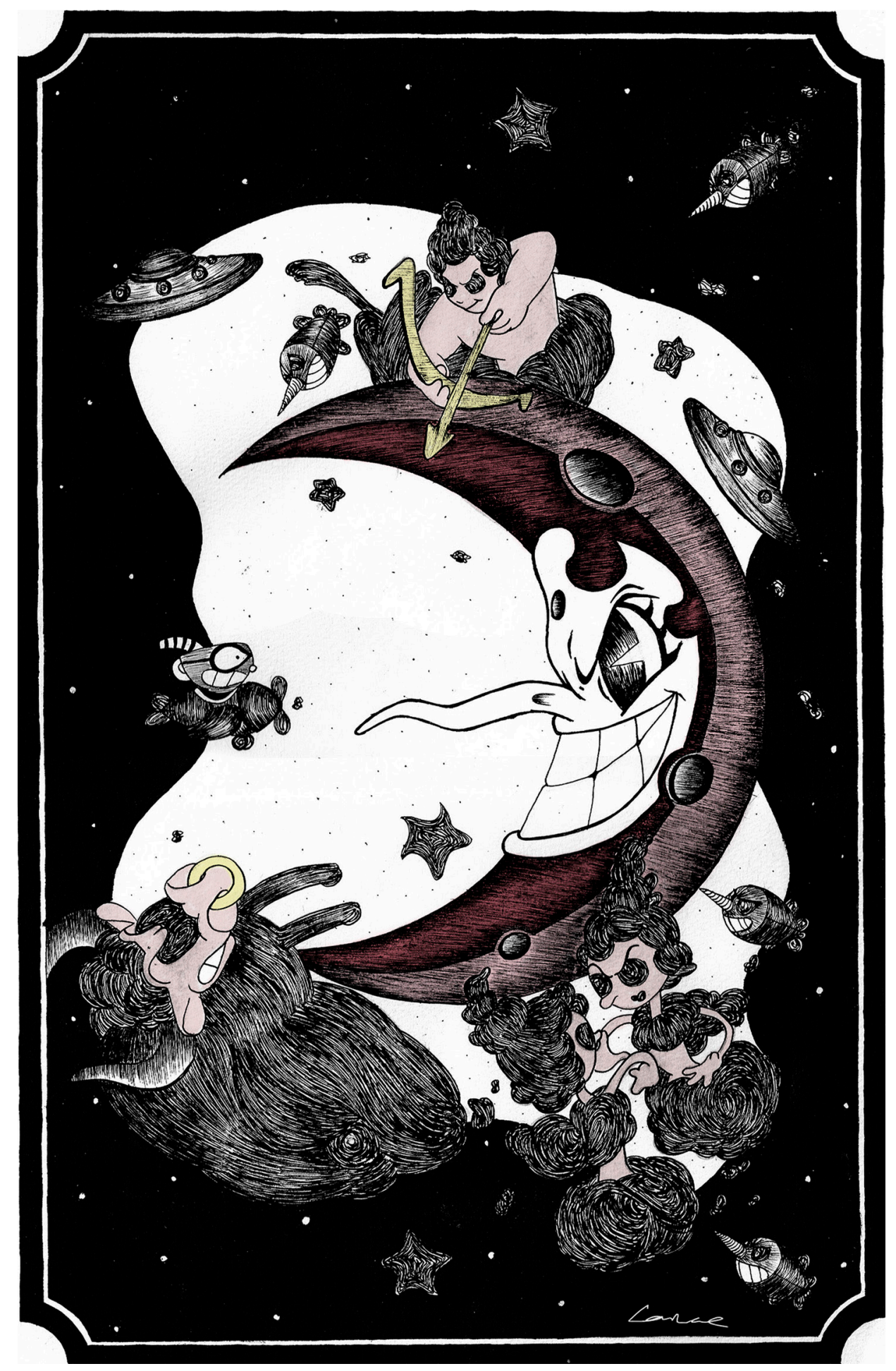

FanArt Cuphead (2017). Tinta china sobre papel de algodón: Larvae (Anel Martínez). Prohibida su reproducción en obras derivadas. 


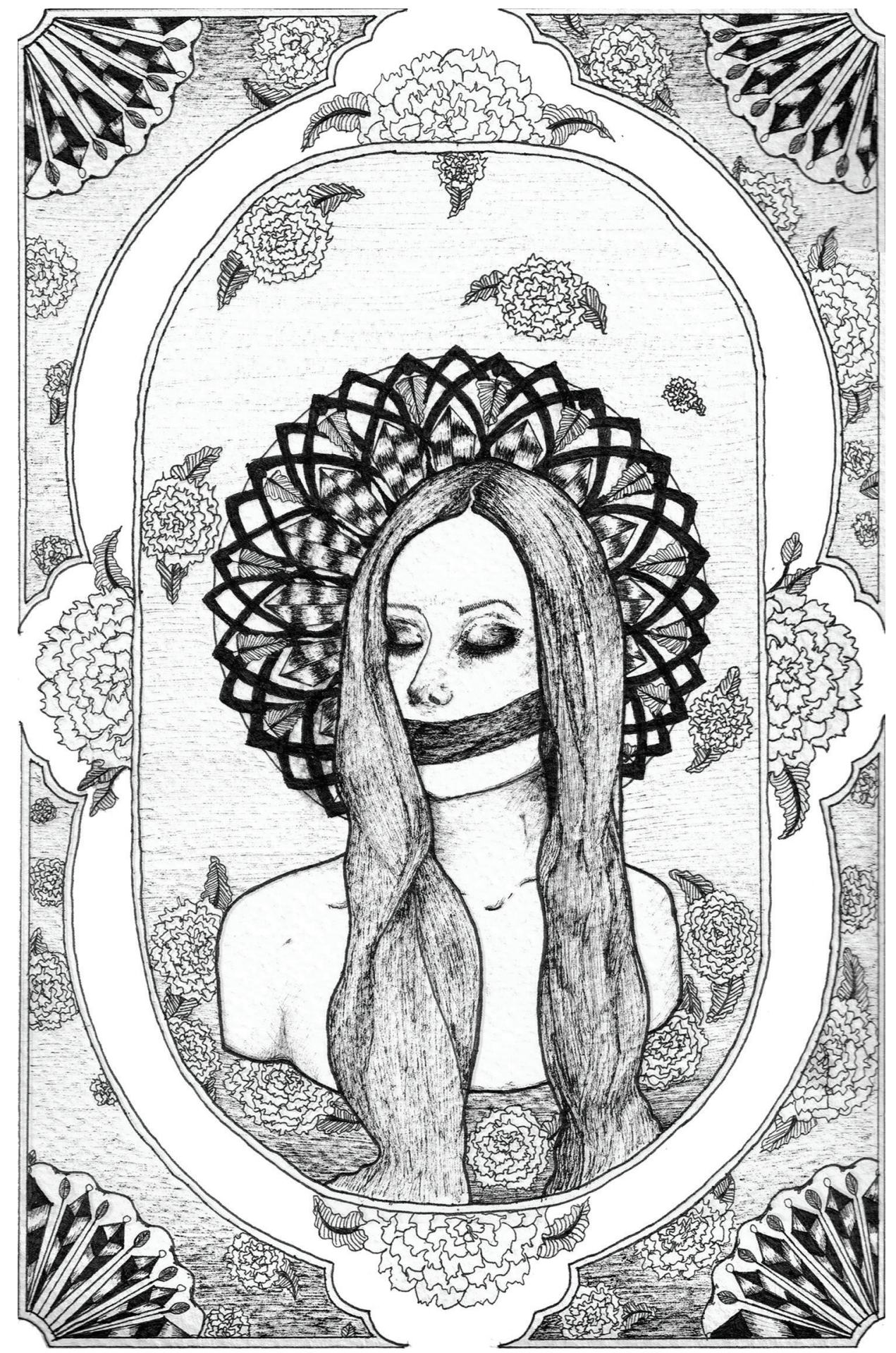

Autorretrato (2015). Tinta china sobre papel de algodón: Larvae (Anel Martínez). Prohibida su reproducción en obras derivadas. 


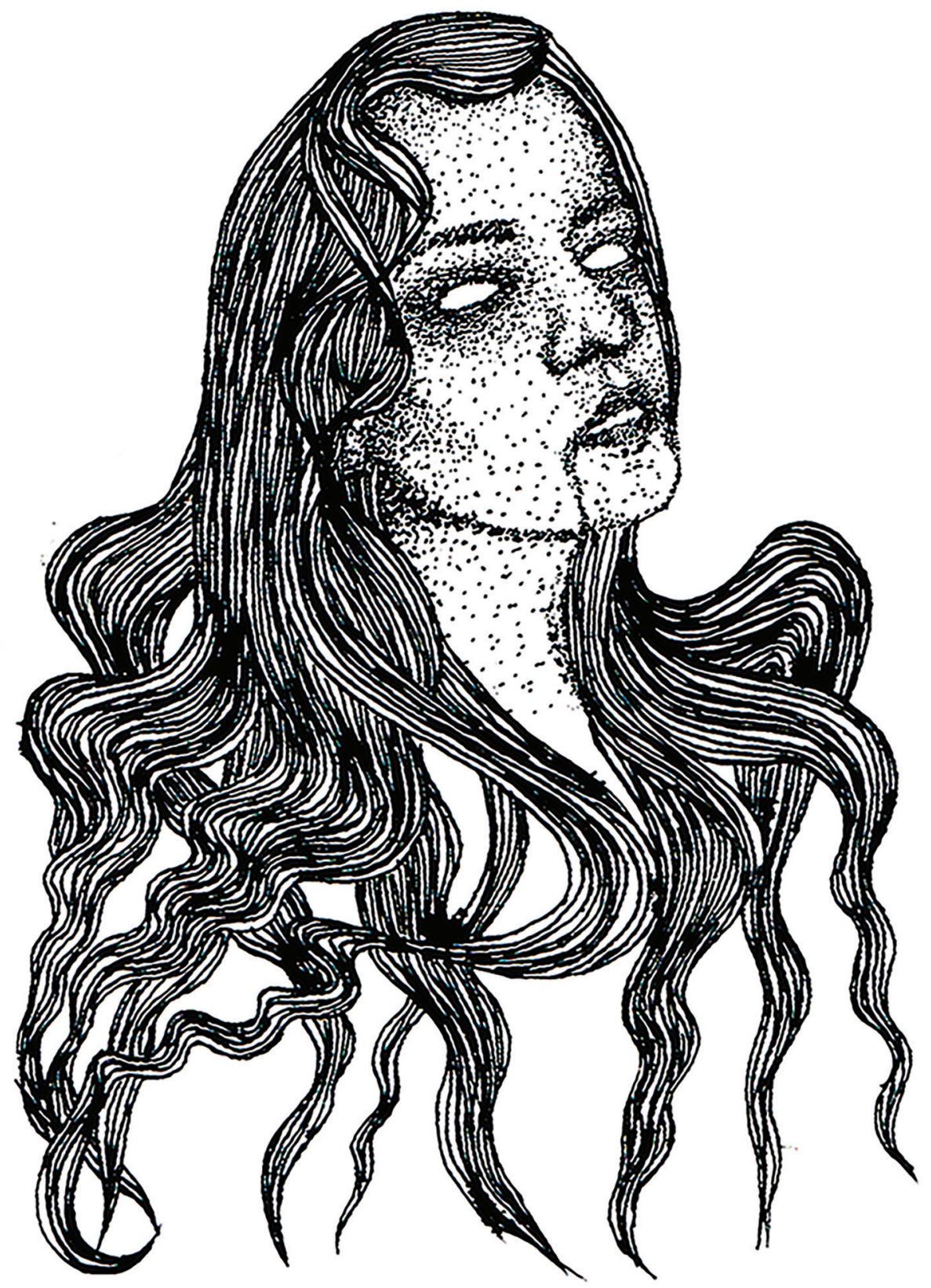

Witch (2018). Tinta china sobre papel de algodón. Larvae (Anel Martínez).

Prohibida su reproducción en obras derivadas. 


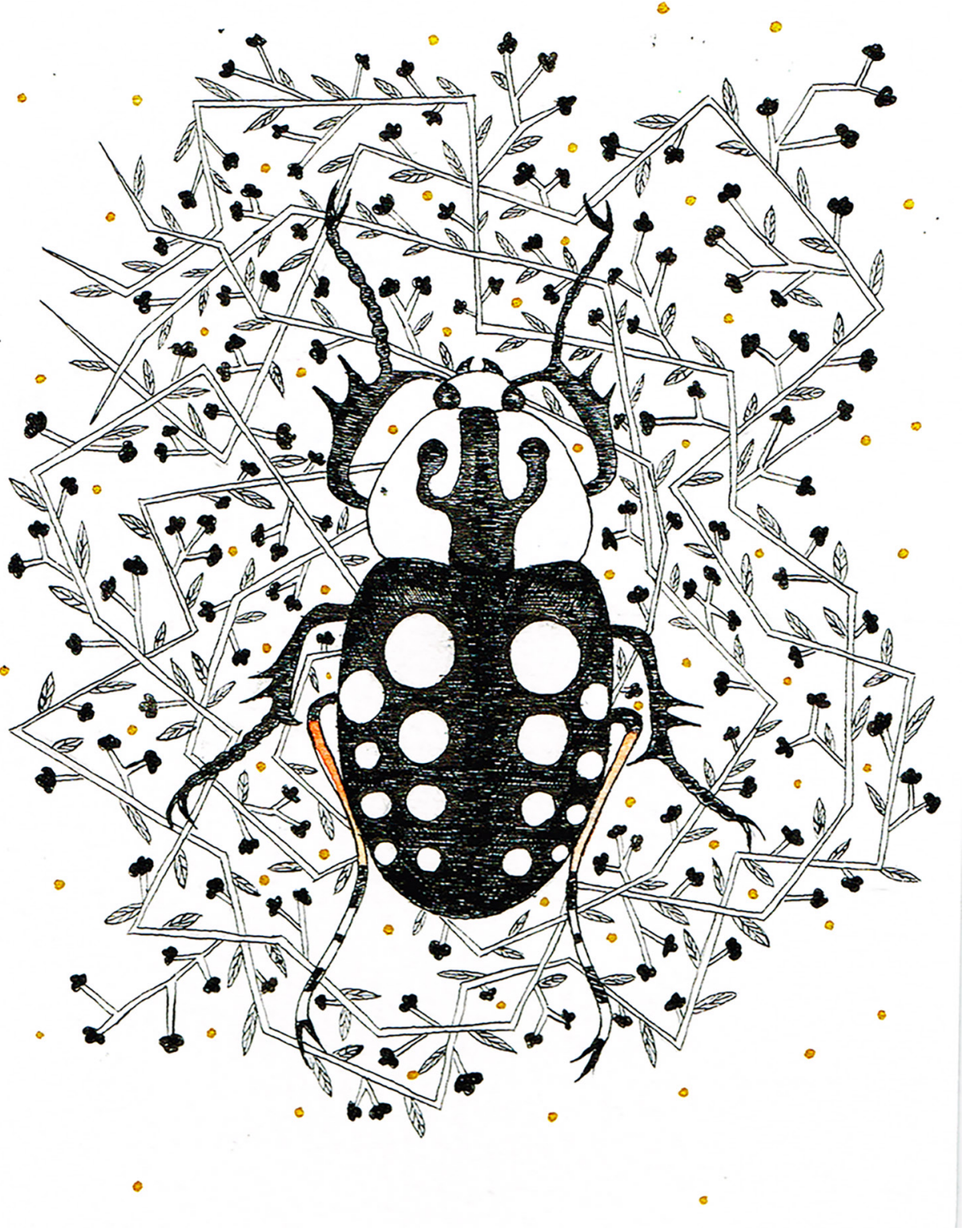




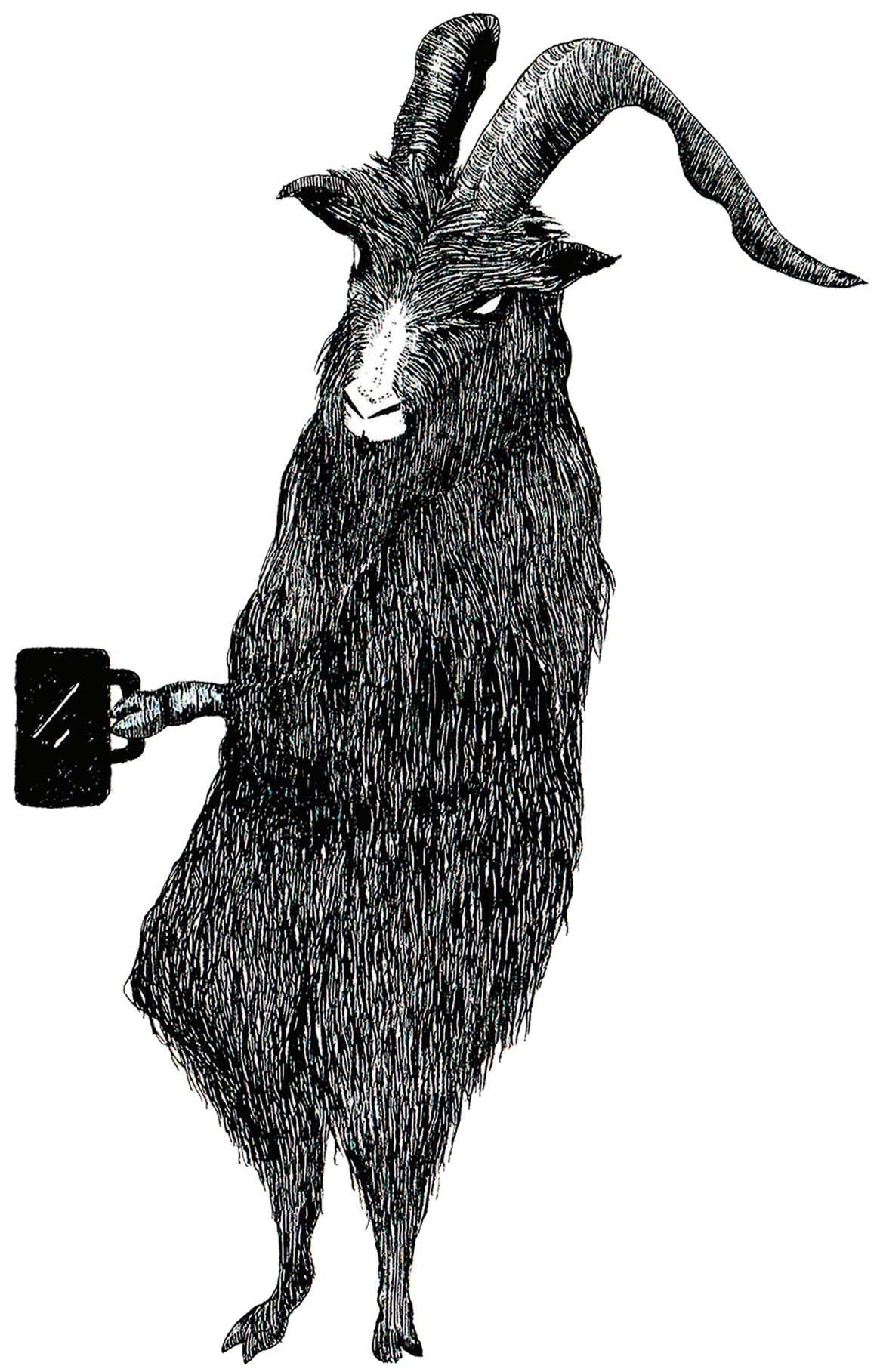

Hello Black Phillip (2018). Tinta china sobre papel de algodón: Larvae (Anel Martínez).

Prohibida su reproducción en obras derivadas. 
Anel Martinez. Artista originaria de la ciudad de Toluca, donde estudió la Licenciatura en Artes Plásticas y se especializó en el arte de concepto. Tomó el seudónimo de Larvae en 2012 después de escuchar uno de los singles de la banda australiana Portal. Su obra explora la música, el terror, la ciencia ficción, los comics y los cuentos. Ha participado en exposiciones colectivas de ilustración. Realizó propaganda para bandas internacionales como 1000 mods y portadas de discos para la banda Thule.

María José Gallardo Rubio. Licenciada en Letras Latinoamericanas por la Universidad Autónoma del Estado de México (UAEM). Investigadora independiente. Sus intereses académicos se centran en la literatura hispanoamericana del siglo XX, estudios comparados entre literatura, pintura y cine, teoría del arte, estética y traducción literaria. Colabora en los periódicos Primero Editores y Estampa Media con temas relacionados con la literatura, el arte y la cultura.

Recibido: 7 de febrero de 2019

Aprobado: 25 de marzo de 2019

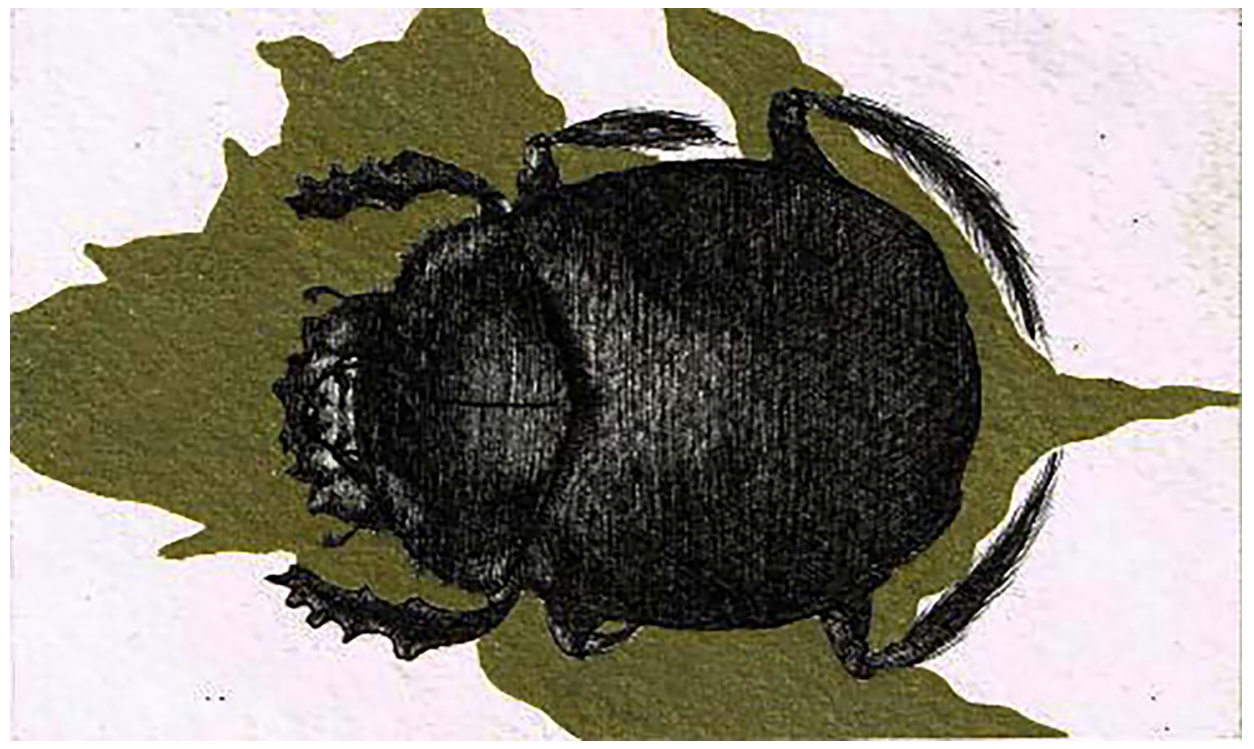

Terra (2017). Tinta china sobre papel de algodón: Larvae (Anel Martínez). Prohibida su reproducción en obras derivadas. 